\title{
Cross-Linkable Epoxidized Maleinated Castor Oil: A Renewable Resin Alternative to Unsaturated Polyesters
}

\author{
Yeşim Müge Şahin,, Gökhan Çaylı, ${ }^{2}$ Jesmi Çavuşoğlu, ${ }^{3}$ Emre Tekay, ${ }^{4}$ and Sinan Şen ${ }^{4}$ \\ ${ }^{1}$ Department of Biomedical Engineering, Istanbul Arel University, 34537 Istanbul, Turkey \\ ${ }^{2}$ Department of Engineering Sciences, Istanbul University, 34320 Istanbul, Turkey \\ ${ }^{3}$ Department of Chemistry, Bogazici University, 34342 Istanbul, Turkey \\ ${ }^{4}$ Department of Polymer Engineering, Yalova University, 77100 Yalova, Turkey
}

Correspondence should be addressed to Yeşim Müge Şahin; ymugesahin@arel.edu.tr

Received 11 March 2016; Revised 6 June 2016; Accepted 7 June 2016

Academic Editor: Luc Averous

\begin{abstract}
Copyright (C) 2016 Yeșim Müge Şahin et al. This is an open access article distributed under the Creative Commons Attribution License, which permits unrestricted use, distribution, and reproduction in any medium, provided the original work is properly cited.
\end{abstract}

\begin{abstract}
As an alternative resin to conventional synthetic unsaturated polyesters (UPEs), epoxidized maleinated castor oil (EMACO) was synthesized in two steps. For this purpose, castor oil was reacted with maleic anhydride at $70^{\circ} \mathrm{C}$ to obtain maleinated castor oil (MACO). Then, epoxidation of MACO was carried out by using a mixture of formic acid and hydrogen peroxide at $0-5^{\circ} \mathrm{C}$. Then, the free carboxyl groups of the synthesized EMACO were further reacted with free epoxide groups of EMACO at $90^{\circ} \mathrm{C}$. At the end of the reaction, an unsaturated polyester precursor-prepolymer was obtained (P-EMACO). FTIR and ${ }^{1} \mathrm{H}$ NMR spectroscopic techniques were used to characterize the monomers synthesized. The P-EMACO was then mixed with styrene and cross-linked in the presence of AIBN at $50^{\circ} \mathrm{C}$. Thermal and mechanical properties of the final cross-linked product were investigated by thermogravimetric analysis (TGA) and dynamic mechanical analysis (DMA) techniques. The degradation onset temperature of the material at which cross-linked X-EMACO loses $5 \%$ of its weight was found to be $209^{\circ} \mathrm{C}$. Its dynamic $T_{g}$ and storage modulus at $25^{\circ} \mathrm{C}$ were determined as $72^{\circ} \mathrm{C}$ and $1.08 \mathrm{GPa}$, respectively. These results are higher than some of the different oil based polymers reported in the literature.
\end{abstract}

\section{Introduction}

Unsaturated polyesters (UPEs) are one of the most versatile and important liquid casting resins. They are produced by the reaction between dibasic acids or anhydrides with glycols. For UPE production, phthalic and maleic anhydrides or their free acids are the mostly used anhydrides and ethylene glycol and propylene glycols are typically used glycols. Depending on the application areas, the ratio of these constituents in unsaturated polyesters can be adjusted [1-5].

Despite its usefulness, synthesis of UPE is not easy. During the production of UPEs, starting temperature is typically around $100^{\circ} \mathrm{C}$ and then the temperature is raised to $180-240^{\circ} \mathrm{C}$ for $16-20$ hours [1-5]. Since high temperature is required in the reaction, it needs high energy consumption which is the disadvantage of the process. In addition to undesired high energy requirement in the UPE synthesis, the abovementioned main components of these resins are almost derived from petroleum sources. Due to the depletion of petroleum reserves and environmental concerns, synthesis of alternative materials from renewable resources can be thought to be an alternative method to the synthetic one.

Protein, carbohydrate, and oil based materials are readily obtainable in nature. Among the renewable resources, plant oil triglycerides are one of the most important materials. A wide variety of polymers can be synthesized from plant oil based chemicals. The mechanical properties of the synthesized polymers can be tuned by using plant oil based chemicals alone or together with petroleum based chemicals [6-8]. Plant oils can be directly polymerized without any modification by reaction of triglycerides with some reagents such as resoles, sulphur, and oxygen [9-11] or simple plant oil triglycerides can be functionalized for polymerization. By using reactive parts of plant oil triglycerides such as ester groups, double bonds, allylic positions, and $\alpha$ carbon to 
the carbonyl group, one can modify the triglycerides with polymerizable groups [12].

Instead of modification of triglycerides, naturally functional triglycerides can also be used for polymerizations. In terms of total production, castor oil is one of the world's most important industrial vegetable oils which contains homoallylic hydroxyl groups inherently [13].

In this work, as an alternative to UPE resins, synthesis, polymerization, and cross-linking of epoxidized maleinated castor oil are reported. For this purpose, the castor oil was first maleinated by using maleic anhydride and then the maleinated castor oil (MACO) was epoxidized (EMACO). Under mild conditions, EMACO was further reacted itself in order to obtain an epoxidized maleinated castor oil precursor (P-EMACO) as an alternative resin to synthetic UPE resins. The P-EMACO was then mixed with $30 \%$ of styrene with respect to the total weight and polymerized/crosslinked to obtain cross-linked EMACO-Styrene copolymer (X-EMACO). The synthesized materials were characterized by FTIR, ${ }^{1} \mathrm{H}$ NMR, and DSC techniques. The thermal and mechanical performances of cross-linked material were investigated by thermogravimetric analysis (TGA) and dynamic mechanical analysis (DMA), respectively.

\section{Materials and Methods}

Castor oil was purchased from Aklar Kimya (Istanbul, Turkey) and used without any purification. Hydroxyl value and iodine number of castor oil were within 160-168 and 8388 , respectively. Dichloromethane, deuterochloroform, formic acid, concentrated hydrochloric acid solution, 30\% hydrogen peroxide solution, maleic anhydride (MA), dimethyl amino pyridine (DMAP), sodium sulfate, tetrahydrofuran (THF), and triethylamine (TEA) were supplied from Merck (Darmstadt, Germany) and all materials were used as they were received.

IR characterizations were performed by Nicolet 380 FTIR spectrometer with Smart Diamond ATR. The ${ }^{1} \mathrm{H}$ NMR spectra were recorded on a Varian $400 \mathrm{MHz}$ NMR instrument operating at a frequency of $399.986 \mathrm{MHz}$ for proton. Thermogravimetric analysis (TGA) was performed with a TGA-Q50 instrument (TA Instruments, New Castle, DE, USA) under nitrogen flow with a heating rate of $10^{\circ} \mathrm{C} / \mathrm{min}$.

Dynamic mechanical properties were measured with a dynamic mechanical analyzer (DMA Q800, TA Instruments, New Castle, DE) in single cantilever mode at a frequency of $1 \mathrm{~Hz}$ and at a heating rate of $3^{\circ} \mathrm{C} / \mathrm{min}$. The samples for the DMA experiments were prepared with a microtome into rectangular shapes having the average dimensions of $12 \times 35$ $\times 3 \mathrm{~mm}^{3}$.

2.1. Maleination of Castor Oil (MACO). Maleination of castor oil was performed according to literature $[14,15]$. The process was modified. For a typical reaction, in a two-necked $250 \mathrm{~mL}$ round bottom flask, $10 \mathrm{~g}$ of castor oil (CO) $(0.0108 \mathrm{~mol})$ was dissolved in $25 \mathrm{~mL}$ of THF and mixed with $4.92 \mathrm{~g}$ of TEA $(0.0487 \mathrm{~mol})$. The solution was cooled to $5^{\circ} \mathrm{C}$ in an ice bath and the solution of $4.77 \mathrm{~g}$ of maleic anhydride $(0.0487 \mathrm{~mol})$ in $10 \mathrm{~mL}$ dry THF was added dropwise in 30 minutes. The mixture was refluxed overnight under nitrogen. After completion of the reaction, the product was vacuum-evaporated and dissolved in $50 \mathrm{~mL}$ dichloromethane and washed with first $50 \mathrm{~mL} 0.1 \mathrm{~N} \mathrm{HCl}$ solution and then $50 \mathrm{~mL}$ saturated salt solution several times in a $250 \mathrm{~mL}$ separatory funnel. After drying over dry sodium sulfate, maleinated castor oil (MACO) was obtained by vacuum-evaporation (Figure 1).

2.2. Epoxidation of MACO. In a $250 \mathrm{~mL}$ flask, $20 \mathrm{~g}$ of $\mathrm{MACO}$ $(0.0168 \mathrm{~mol})$ was mixed with $7.86 \mathrm{~g}$ of formic acid $(0.17 \mathrm{~mol})$. While vigorously stirring this mixture, $12.32 \mathrm{~g}$ of $30 \% \mathrm{H}_{2} \mathrm{O}_{2}$ solution $(0.109 \mathrm{~mol})$ was added to this mixture. The mixture was then stirred approximately at room temperature for 30 hours. After completion of the reaction, the crude product was dissolved in $50 \mathrm{~mL}$ of dichloromethane and placed in a separatory funnel and washed first with approximately $50 \mathrm{~mL}$ of distilled water three times. Then, the product was washed with approximately $100 \mathrm{~mL}$ of saturated sodium bicarbonate solution. The last step was repeated until upper water layer was neutral. Then, the organic layer was washed with $50 \mathrm{~mL}$ of saturated sodium chloride solution. Dichloromethane layer was dried over anhydrous sodium sulfate. The sodium sulfate was filtered off, and the dichloromethane was evaporated. The crude product (EMACO) was used without any further purification.

2.3. Synthesis of EMACO Precursor-Prepolymer (P-EMACO). In a $250 \mathrm{~mL}$ round bottom flask, $10 \mathrm{~g}$ of EMACO was dissolved in $50 \mathrm{~mL}$ dioxane and $0.05 \mathrm{~g}$ of DMAP was added to this mixture. To prevent polymerization reactions, $0.01 \mathrm{~g}$ of hydroquinone was also added to the system. The mixture was heated to $90^{\circ} \mathrm{C}$ under nitrogen atmosphere and the reaction continued for 10 hours. After the reaction was completed, solvent was evaporated and the product was used without any further purification.

2.4. Synthesis of Cross-Linked EMACO (X-EMACO). Styrene ( $30 \%$ of the monomer by weight) and AIBN ( $1 \%$ of the styrene monomer mixture) were mixed with P-EMACO until all the initiator was dissolved. Then, the solution was purged with nitrogen for 10 minutes and the tube was sealed. The mixture was left to wait overnight at $50^{\circ} \mathrm{C}$.

\section{Results and Discussions}

3.1. Characterization of Monomers. In order to characterize the monomers synthesized, FTIR and ${ }^{1} \mathrm{H}$ NMR techniques were used. FTIR spectra of castor oil (CO), MACO, and EMACO are depicted in Figure 2. The castor oil spectrum showed a peak at $3400 \mathrm{~cm}^{-1}$ due to the presence of $\mathrm{OH}$ groups. Peak at $3008 \mathrm{~cm}^{-1}$ belonged to $\mathrm{C}-\mathrm{H}$ vibration of the double bond hydrogen atoms. The peaks at 2920 and $2850 \mathrm{~cm}^{-1}$ were observed due to the presence of aliphatic $\mathrm{C}-\mathrm{H}$ bonds. The peak of ester carbonyl groups appeared at $1740 \mathrm{~cm}^{-1}$ and a small peak at $1658 \mathrm{~cm}^{-1}$ was detected due to the presence of double bond. When maleinization occurred, the peak at $3400 \mathrm{~cm}^{-1}$ disappeared and a broad peak was observed, which starts from $2600 \mathrm{~cm}^{-1}$ and ended 


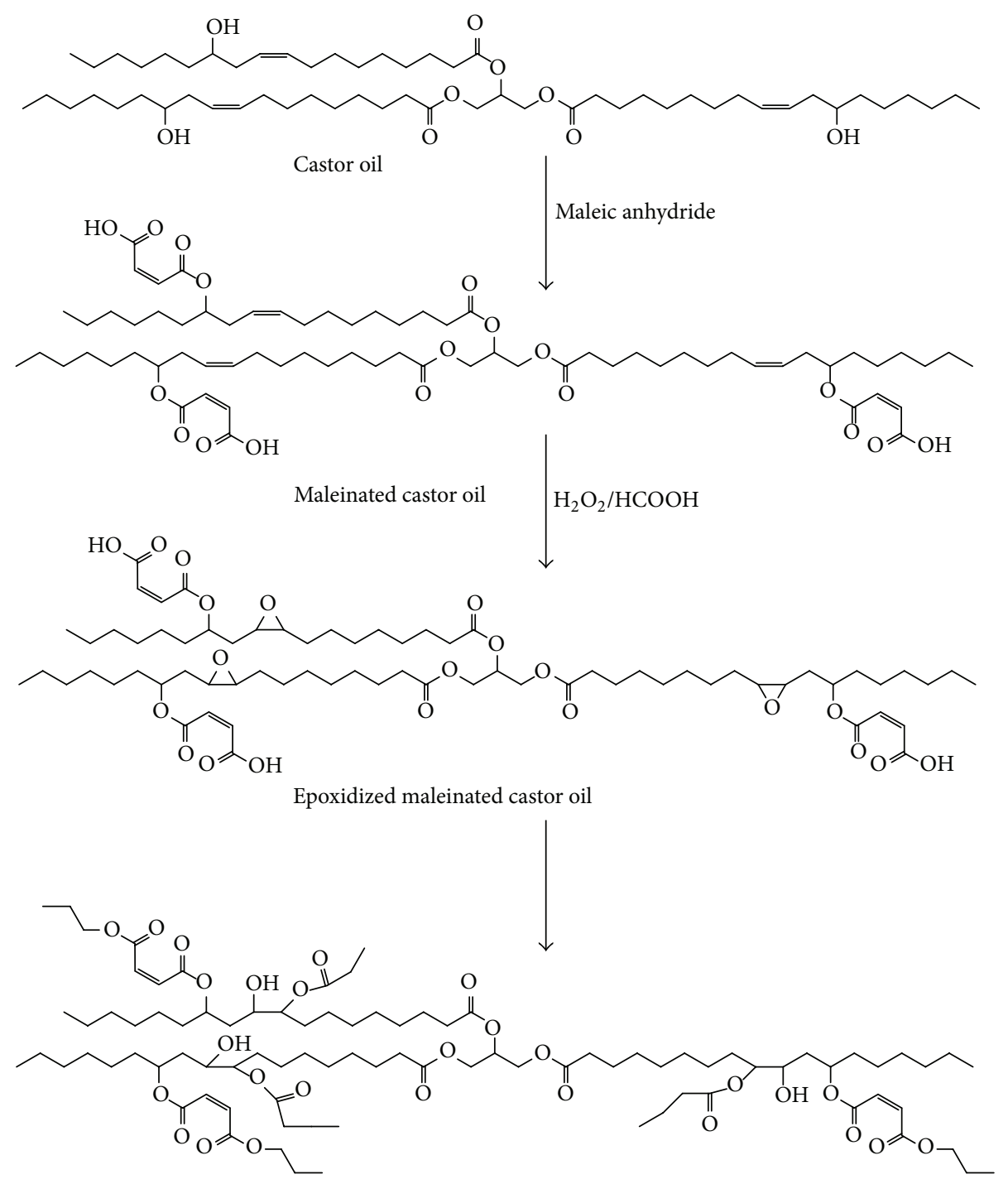

Epoxidized maleinated castor oil precursor

Figure 1: Synthesis of EMACO and P-EMACO.

at $3500 \mathrm{~cm}^{-1}$. The peak of ester carbonyl shifted to $1732 \mathrm{~cm}^{-1}$ and a new peak appeared at $1636 \mathrm{~cm}^{-1}$. These peaks are good indications of the esterification and thus attachment of maleate groups. Moreover, no peaks were observed at 1779 and $1849 \mathrm{~cm}^{-1}$ that belong to maleic anhydride.

When epoxidation occurred, the double bond peaks of the castor oil ought to disappear. Unfortunately, the peaks overlapped with the peaks of maleate groups. Thus, it was not possible to monitor the changes but some following evidences were observed confirming the polymerization. It is known that when the oxirane ring forms, it is expected to react with the free maleate carboxyl's, leading to an increase in $\mathrm{OH}$ peak intensity in the FTIR spectrum and a change in the $\mathrm{C}-\mathrm{O}$ peaks observed at $1400-1000 \mathrm{~cm}^{-1}$ region. These changes were also observed in the related FTIR spectra (Figure 2) and so it can be safely stated that the product was polymerized after epoxidation of maleinated castor oil that we call EMACO precursor/prepolymer (P-EMACO).

${ }^{1} \mathrm{H}$ NMR spectra of the monomers synthesized are shown in Figure 3. The double bond hydrogen atoms of $\mathrm{CO}$ appeared at $5.2-5.3 \mathrm{ppm}$ as two separate multiplets. Two hydrogen atoms of glycerin moiety appeared at 4.0-4.2 and one hydrogen atom appeared at $5.1 \mathrm{ppm}$. The peaks of homoallylic hydrogen atoms could be followed at $3.5 \mathrm{ppm}$

Once maleination occurs, the peak of hydrogen atoms germinal to homoallylic hydroxyls disappeared and a new peak at $4.8 \mathrm{ppm}$ was observed. No peaks at $3.5 \mathrm{ppm}$ were detected which meant that all $\mathrm{OH}$ groups were converted to maleate ester. Moreover, two new peaks were depicted at 7.2 and $5.4 \mathrm{ppm}$ which belong to the maleate hydrogen atoms. One of the best reference hydrogen atoms in castor oil triglyceride is $-\mathrm{CH}_{3}$ groups whose signals appeared around $1.0 \mathrm{ppm}$. 


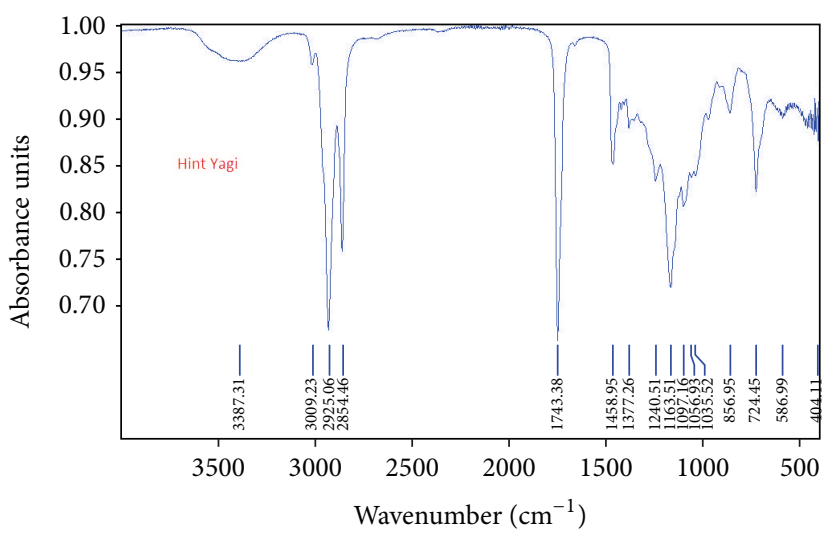

(a)

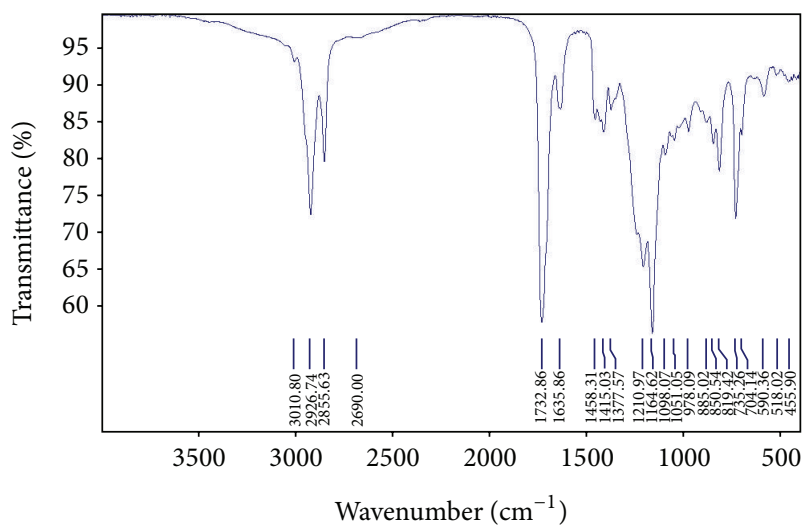

(b)

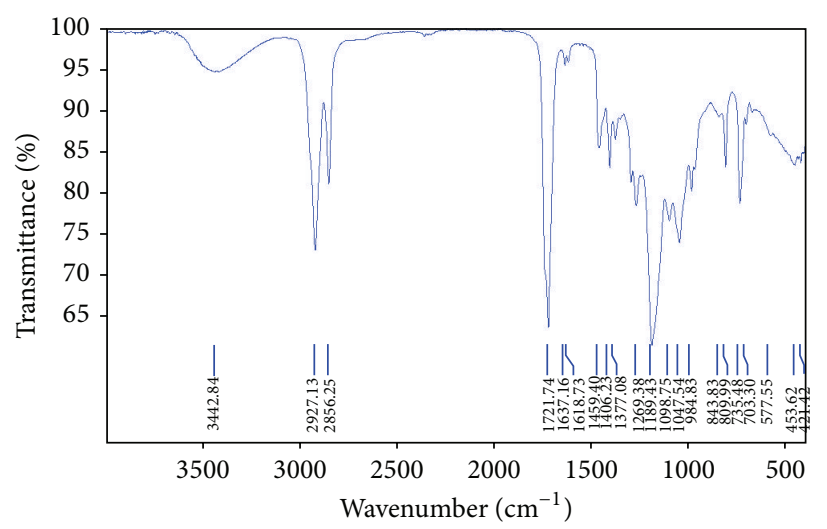

(c)

FIgURE 2: IR spectrum of (a) castor oil, (b) MACO, and (c) P-EMACO.

The amount of these hydrogen atoms per triglyceride is 9 . In the case of MACO, when the integration ratio of maleate hydrogen atoms to $-\mathrm{CH}_{3}$ hydrogen atoms was calculated, the ratio was close to 0.6 . This finding proves that, approximately, 2.7 mol of maleate groups are attached to one mol of castor oil triglyceride. Following epoxidation and polymerization reactions, the peaks of the double bond hydrogen atoms of castor oil disappeared completely in the ${ }^{1}$ HNMR spectrum. Additionally, the peaks of allylic hydrogen atoms at $2.15 \mathrm{ppm}$ also diminished. The peak at $4.8 \mathrm{ppm}$ broadened probably due to the occurrence of new maleate esters. Moreover, a relatively small peak was observed at $5.2 \mathrm{ppm}$ which is most probably due to the presence of maleate esters. Two separate peaks of maleate hydrogen atoms was observed as an intense and broad single peak at $6.4 \mathrm{ppm}$. Many new peaks appeared between 3.5 and $4.1 \mathrm{ppm}$ which might be ascribed to new $\mathrm{OH}$ groups formed after the reaction of epoxy groups with free carboxylic acids. Moreover, no peak was observed at 9-11 ppm region that is an indicator of the presence of free carboxyl groups. This observation also proves that almost all free maleate groups were esterified and consumed by oxirane groups.

3.2. Mechanical and Thermal Properties of Materials. For the evaluation of the mechanical properties of the materials synthesized, DMA technique was used. DMA data of the cross-linked EMACO-Styrene copolymer (X-EMACO) is shown in Figure 4. In the literature, several studies about acrylation, methacrylation, and maleinization of castor oil have been published. In those studies, the final polymers obtained were reported to be different types of viscous or creamy materials due to the presence of allylic positions [16, $17,19]$. Although those are not load-bearing materials, they have good film-forming properties and are used as binder. Moreover, if the double bonds of the castor oil are converted to any suitable group that does not interfere with radical polymerization, it would be possible to obtain hard, strong, and load-bearing materials from maleinated castor oil.

Esen and Çaylı converted acrylated castor oil to epoxidized acrylated castor oil and polymerization of this monomer with $15 \%$ of acrylic acid gave an excellent and transparent material. The storage modulus of this polymer was found to be $0.7 \mathrm{GPa}$ at $25^{\circ} \mathrm{C}$ [20] (Table 1). In the current study, the castor oil was first maleinated and the maleinated castor oil was epoxidized. Then, epoxide ring of the maleinated castor oil was readily reacted with free carboxyl groups of maleate moieties, which is a well-known reaction $[18,21]$. The resultant material was a viscous and cross-linkable as well as styrene soluble liquid precursor (PEMACO). The copolymerization/cross-linking of $70 \%$ of PEMACO with $30 \%$ of styrene gave a tough, load-bearing, and transparent material. The cross-linked polymer (X-EMACO) 


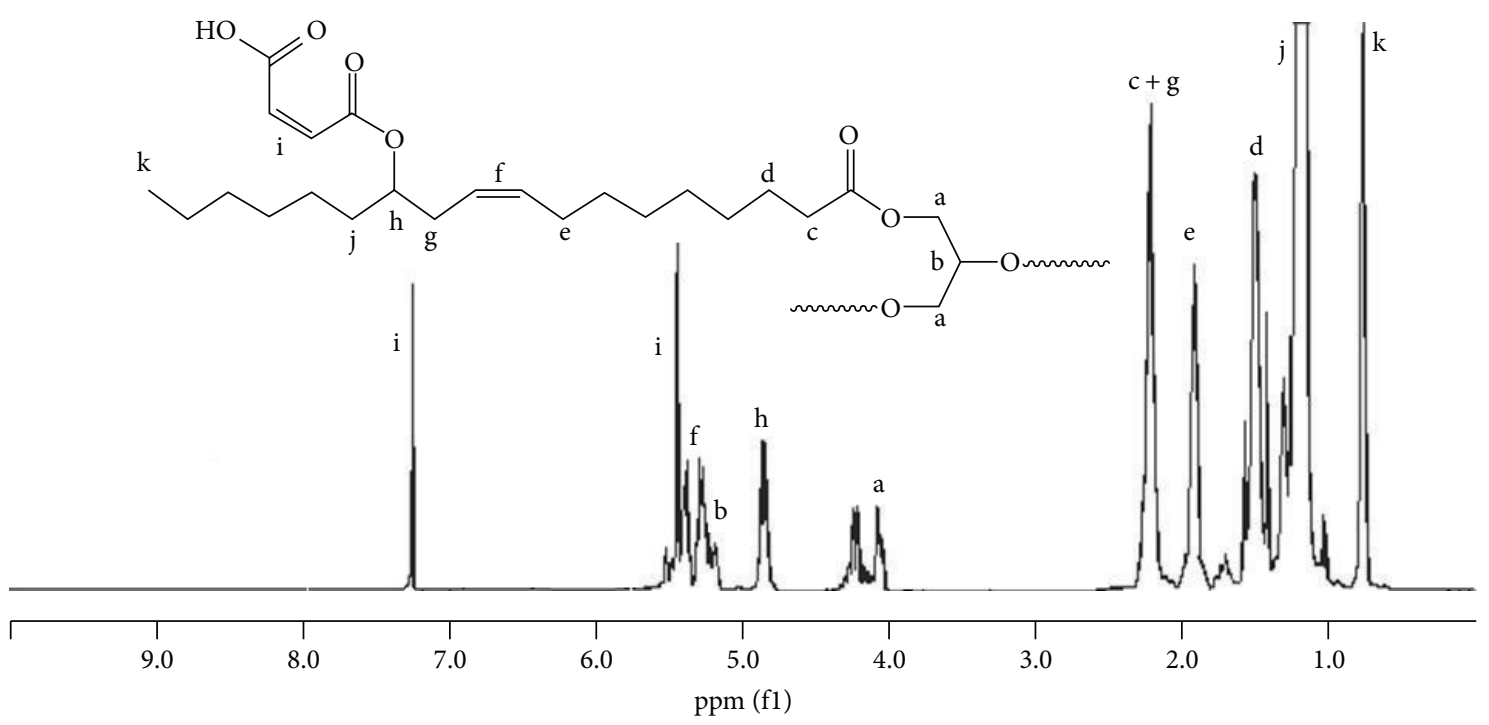

(a)

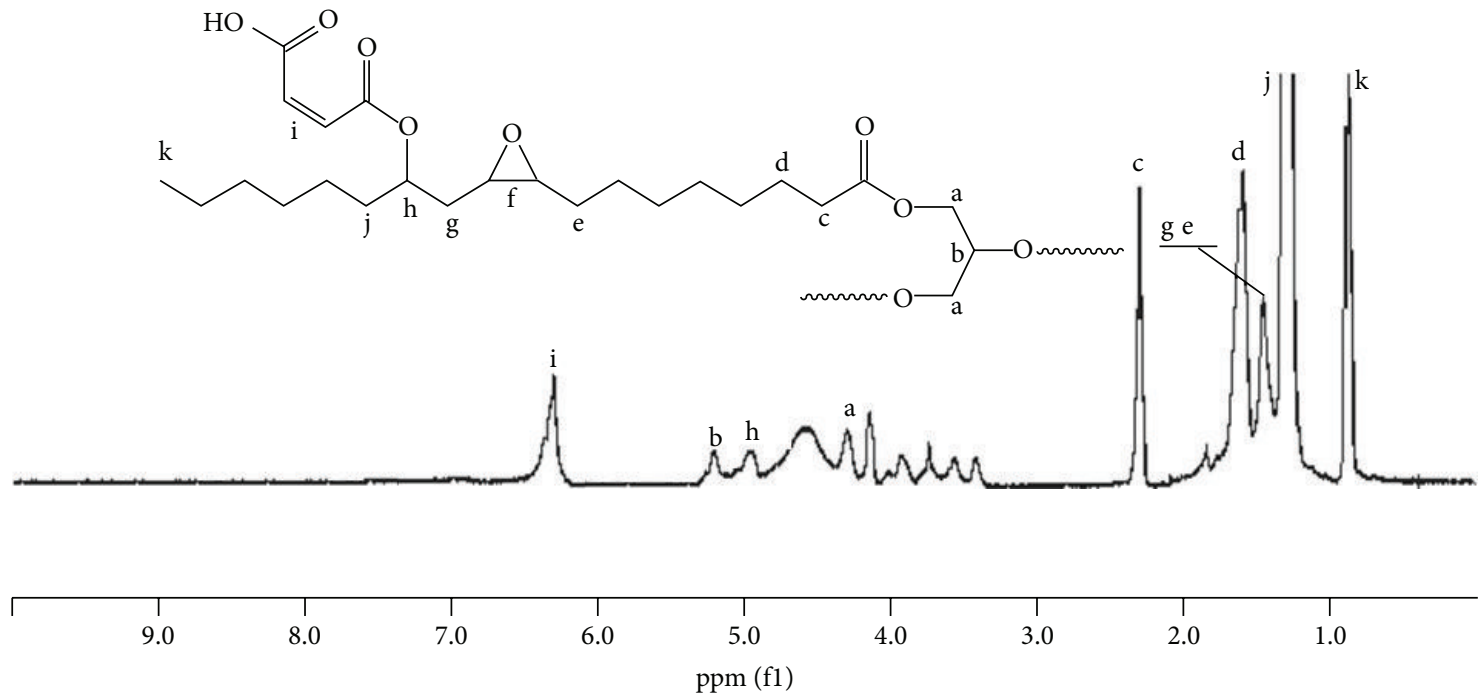

(b)

FIgURE $3:{ }^{1} \mathrm{H}$ NMR spectrum of (a) maleinated castor oil and (b) epoxidized maleinated castor oil.

exhibited a storage modulus of $1.08 \mathrm{GPa}$ at $25^{\circ} \mathrm{C}$ which is ca. 1.5 times higher than that of the abovementioned acrylic acid cross-linked castor oil [20]. The rubbery phase plateau was achieved at about $100^{\circ} \mathrm{C}$ with a rubbery modulus of $14 \mathrm{MPa}$. The X-EMACO was also found to have a dynamic $T_{g}$ of $72^{\circ} \mathrm{C}$ which is higher than $T_{g}\left(61^{\circ} \mathrm{C}\right)$ of the acrylic acid cross-linked castor oil [20] (Table 1) and approaches the range of some conventional unsaturated polyesters.

There is one study [22] reported in the literature that achieved better mechanical properties than those of $\mathrm{X}$ EMACO. In that study, tung oil based unsaturated polyester was cross-linked with $30 \%$ styrene and the resultant polymer was found to have a tensile modulus of $1.9 \mathrm{GPa}$. It was also stated that the reaction mixture of tung oil and pentaerythritol was required to be heated up to $200^{\circ} \mathrm{C}$ which is much higher than that $\left(90^{\circ} \mathrm{C}\right)$ of the synthesis reaction of the P-EMACO. In this regard, our approach seems to be more advantageous since it involves relatively lower energy consumption. Moreover, the novel styrene cross-linked castor oil based polymer (X-EMACO) prepared in this study has also an advantage over some other plant oil based polymers in terms of mechanical strength. For example, Tekay and Şen [23] reported 50\% styrene containing acrylated epoxidized soybean oil (AESO) polymer. It was found to have a storage modulus of $0.9 \mathrm{GPa}$ at $30^{\circ} \mathrm{C}$ and a dynamic $T_{g}$ of $60^{\circ} \mathrm{C}$ (Table 1) which are lower than those of the X-EMACO having $30 \%$ styrene monomer.

Finally, it can be safely stated that even though X-EMACO is not as strong as petroleum based UPEs, it can be a good alternative to plant oil based ones [20, 21, 23] (Table 1).

Thermal stabilities of P-EMACO and X-EMACO were determined by TGA technique. As it can be seen from the 


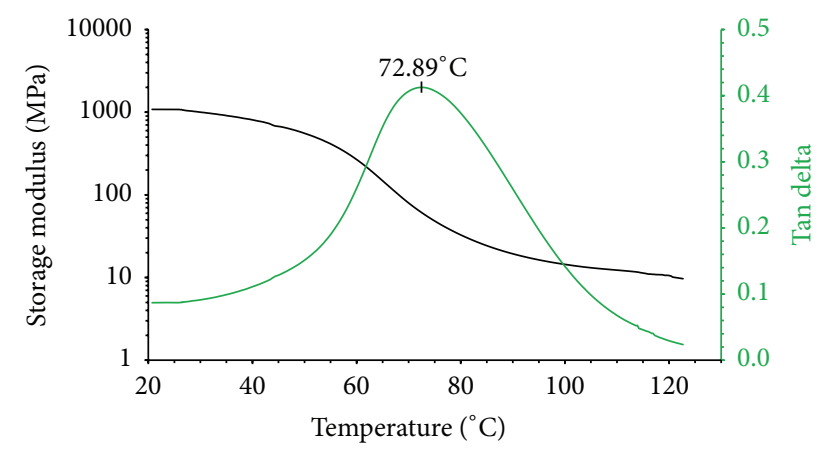

FIGURE 4: DMA plots of the X-EMACO-Styrene copolymer.

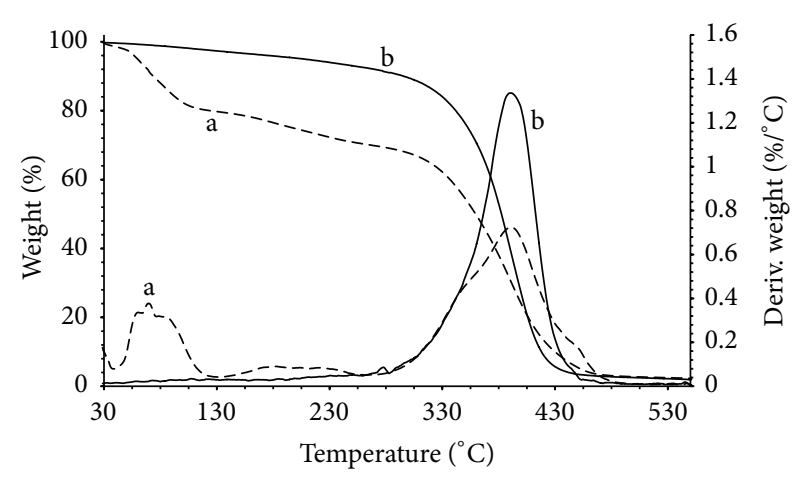

FIGURE 5: TGA thermograms and corresponding derivative curves of the (a) P-EMACO and (b) X-EMACO-Styrene copolymer.

TABLE 1: The comparative storage modulus values of different oil based polymer copolymers/networks.

\begin{tabular}{lcc}
\hline Materials & $\begin{array}{c}\text { Storage } \\
\text { modulus }(\mathrm{GPa})\end{array}$ & $\begin{array}{c}\text { Dynamic } T_{g} \\
\left({ }^{\circ} \mathrm{C}\right)\end{array}$ \\
\hline X-EMACO & $1.08\left(\right.$ at $\left.25^{\circ} \mathrm{C}\right)$ & 72 \\
EACO-AA $^{\text {a }}[16]$ & $0.70\left(\right.$ at $\left.25^{\circ} \mathrm{C}\right)$ & 61 \\
MESO-St $^{\mathrm{b}}[17]$ & $0.1\left(\right.$ at $\left.25^{\circ} \mathrm{C}\right)$ & 55 \\
AESO-St $^{\mathrm{c}}[18]$ & $0.9\left(\right.$ at $\left.30^{\circ} \mathrm{C}\right)$ & 60 \\
\hline
\end{tabular}

${ }^{a}$ EACO-AA: epoxidized acrylated castor oil copolymerized with 15 wt. $\%$ acrylic acid.

${ }^{b}$ MESO: monomethyl maleic esters of epoxidized soybean oil copolymerized with 60 wt.\% styrene.

${ }^{c}$ AESO-St: acrylated epoxidized soybean oil copolymerized with 50 wt.\% styrene.

thermogram of P-EMACO (Figure 5), most of the weight loss seemed to occur after $300^{\circ} \mathrm{C}$ which is an indication of prepolymer/precursor structure. For X-EMACO, the decomposition onset temperature at which 5\% weight is lost was measured as $209^{\circ} \mathrm{C}$. It was also found to be stable thermally up to $300^{\circ} \mathrm{C}$ which is higher than that $\left(250^{\circ} \mathrm{C}\right)$ of monomethyl maleic ester of epoxidized soybean oil copolymerized with vinyl acetate as a different oil based UPE [21].

\section{Conclusions}

In this study, epoxidation reaction of maleinated castor oil without disturbing maleate double bonds was carried out.
After the epoxidation reaction, EMACO was successfully turned to unsaturated polyester by the ring opening reaction between oxirane groups and the free carboxyl ends of maleate groups. As a result, a transparent and viscous precursor-prepolymer was obtained via both intermolecular and intramolecular esterification reactions. The product was dissolved in styrene and cross-linked. The product was a hard, tough, and transparent material. The cross-linked copolymer synthesized showed better mechanical properties than some other plant oil based copolymers/networks such as AESO and castor oil. This novel resin can find applications as a biobased UPE where improved mechanical properties are needed.

\section{Competing Interests}

The authors declare that they have no competing interests.

\section{References}

[1] K. Keinänen and G. Wigington, "Unsaturated polyester resins," US Patent, 6,268,464 B1, 2001.

[2] I. H. Updegraff, "Unsaturated polyester resins," in Handbook of Composites, I. H. Updegraff and G. Lubin, Eds., section 1, pp. 17-37, Springer, Berlin, Germany, 1981.

[3] R. F. Russell, "Unsaturated polyester resins," U.S. patent, 4,285,845 A, 1981.

[4] H. Nava, "Polyesters, unsaturated," in Encyclopedia of Polymer Science and Technology, John Wiley \& Sons, New York, NY, USA, 2004.

[5] K. J. Saunders, Organic Polymer Chemistry, Springer, Amsterdam, The Netherlands, 1973.

[6] S. Miao, P. Wang, Z. Su, and S. Zhang, "Vegetable-oil-based polymers as future polymeric biomaterials," Acta Biomaterialia, vol. 10, no. 4, pp. 1692-1704, 2014.

[7] K. F. Adekunle, "A review of vegetable oil-based polymers: synthesis and applications," Open Journal of Polymer Chemistry, vol. 5, pp. 34-40, 2015.

[8] S. N. Khot, J. J. Lascala, E. Can et al., "Development and application of triglyceride-based polymers and composites," Journal of Applied Polymer Science, vol. 82, no. 3, pp. 703-723, 2001.

[9] G. Çaylı and S. Küsefoğlu, "Polymerization of linseed oil with phenolic resins," Journal of Applied Polymer Science, vol. 118, no. 2, pp. 849-856, 2010.

[10] H. Ebata, M. Yasuda, K. Toshima, and S. Matsumura, "Poly (ricinoleic acid) based novel thermosetting elastomer," Journal of Oleo Science, vol. 57, no. 6, pp. 315-320, 2008.

[11] M. A. R. Meier, J. O. Metzger, and U. S. Schubert, "Plant oil renewable resources as green alternatives in polymer science," Chemical Society Reviews, vol. 36, no. 11, pp. 1788-1802, 2007.

[12] G. Lligadas, J. C. Ronda, M. Galiá, and V. Cádiz, "Plant oils as platform chemicals for polyurethane synthesis: current state-ofthe-art," Biomacromolecules, vol. 11, no. 11, pp. 2825-2835, 2010.

[13] H. Pelletier and A. Gandini, "Preparation of acrylated and urethanated triacylglycerols," European Journal of Lipid Science and Technology, vol. 108, no. 5, pp. 411-420, 2006.

[14] J. Cavusoglu and G. Çaylı, "Polymerization reactions of epoxidized soybean oil and maleate esters of oil-soluble resoles," Journal of Applied Polymer Science, vol. 132, no. 7, 2015. 
[15] P. C. Mazo, D. Estenoz, and L. A. Ríos, "Kinetics of the esterification of maleic anhydride with castor oil," Latin American Applied Research, vol. 41, no. 1, pp. 11-15, 2011.

[16] B. F. Dillman, N. Y. Kang, and J. L. P. Jessop, "Solventless synthesis and free-radical photopolymerization of a castor oilbased acrylate oligomer," Polymer, vol. 54, no. 7, pp. 1768-1774, 2013.

[17] O. S. Kabasakal, F. S. Guner, A. T. Erciyes, and Y. Yagci, "Styrenation of oils based on secondary esters of castor oil," Journal of Coatings Technology, vol. 67, no. 841, pp. 47-51, 1995.

[18] H. Esen and S. H. Küsefoğlu, "Photolytic and free-radical polymerization of cinnamate esters of epoxidized plant oil triglycerides," Journal of Applied Polymer Science, vol. 89, no. 14, pp. 3882-3888, 2003.

[19] M. Gultekin, U. Beker, F. S. Güner, A. T. Erciyes, and Y. Yagci, "Styrenation of castor oil and linseed oil by macromer method," Macromolecular Materials and Engineering, vol. 283, no. 1, pp. 15-20, 2000.

[20] H. Esen and G. Çayll, "Epoxidation and polymerization of acrylated castor oil," European Journal of Lipid Science and Technology, vol. 118, no. 6, pp. 959-966, 2016.

[21] H. Esen, S. Küsefoğlu, and R. Wool, "Photolytic and free-radical polymerization of monomethyl maleate esters of epoxidized plant oil triglycerides," Journal of Applied Polymer Science, vol. 103, no. 1, pp. 626-633, 2007.

[22] C. Liu, X. Yang, J. Cui et al., "Tung oil based monomer for thermosetting polymers: synthesis, characterization and copolymerization with styrene," BioResources, vol. 7, no. 1, pp. 447-463, 2012.

[23] E. Tekay and S. Şen, “Tuning of final performances of soybean oil-based polymer nanocomposites: effect of styryl/oil functionalized intercalant of montmorillonite reinforcer," International Polymer Processing, vol. 30, no. 2, pp. 248-255, 2015. 

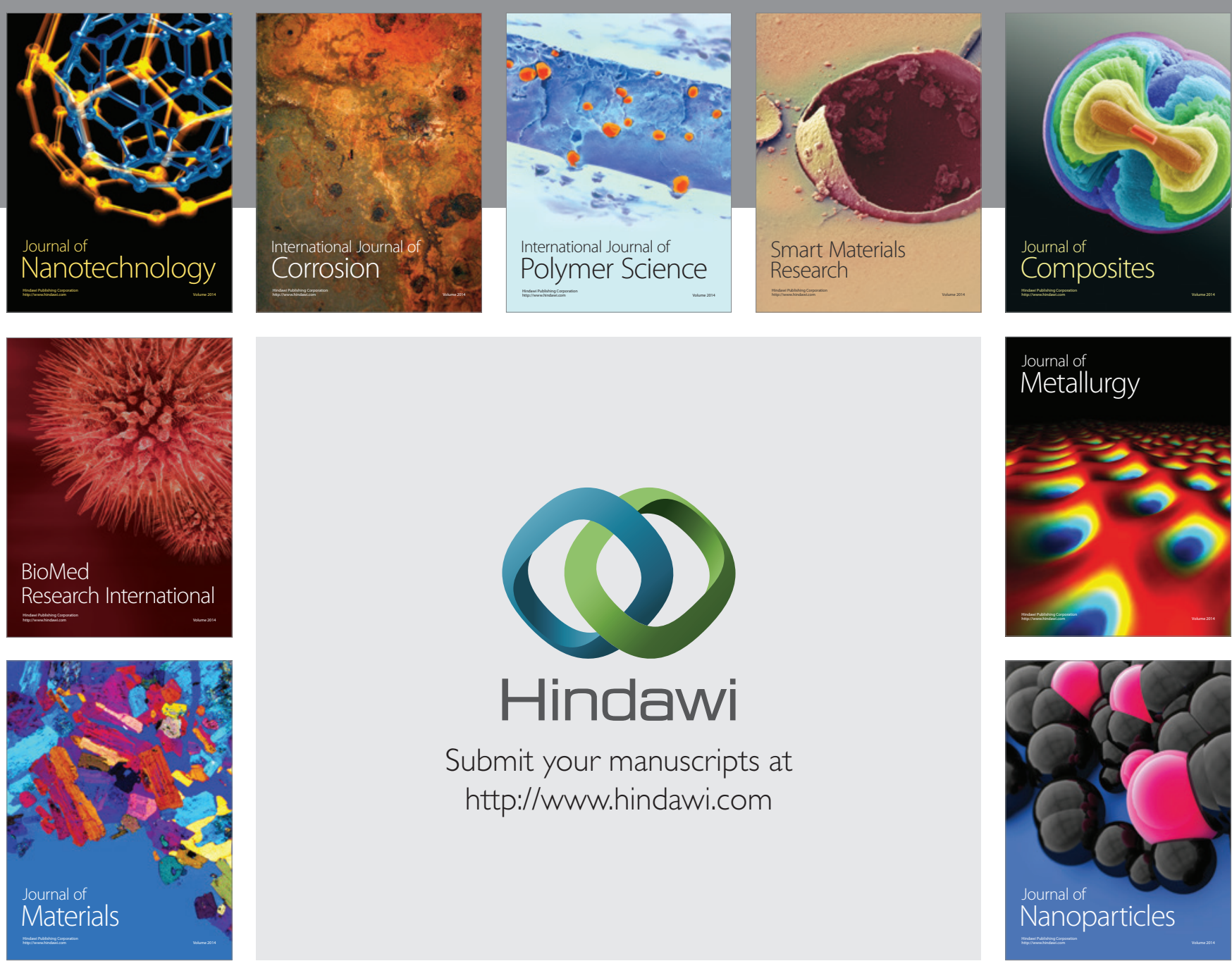

\section{Hindawi}

Submit your manuscripts at

http://www.hindawi.com

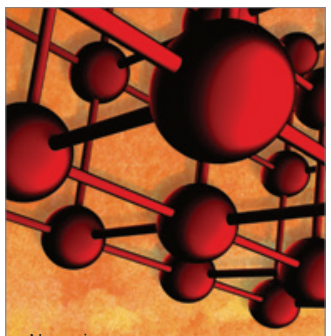

Materials Science and Engineering
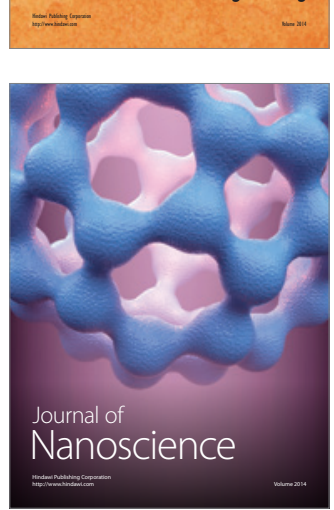
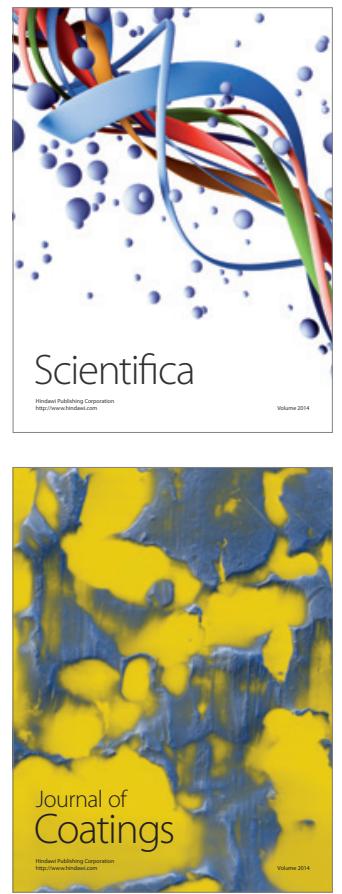
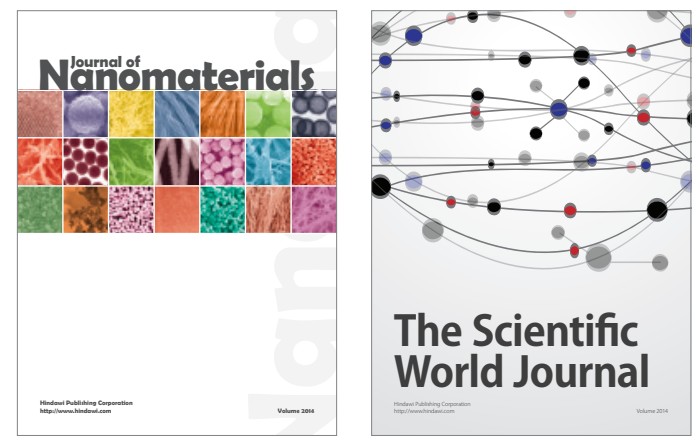

The Scientific World Journal
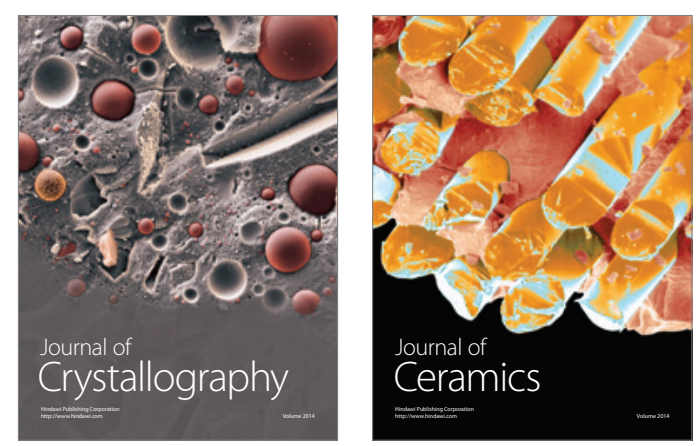
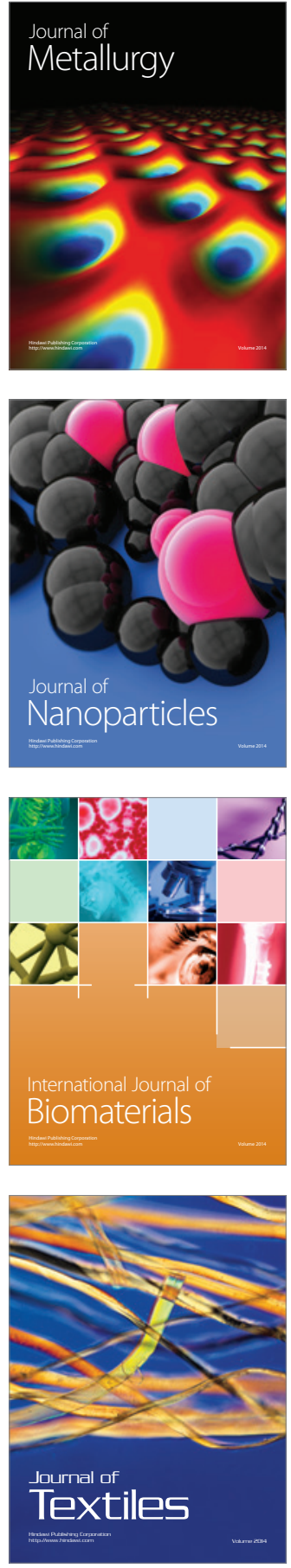